\title{
Effect of Peripheral Blood Mononuclear Cells on Induced Ischemia/Reperfusion in Skeletal Muscle of Adult Male Albino Rat: An Immunohistochemical Study
}

\author{
Hend I. Abd El Halim*, Reda H. Elbakary, Ebtsam F. Okasha, \\ Amany M. Mousa and Ehsan F. Salah
}

Histology Department, Tanta University, Tanta, Egypt

*Corresponding author

\section{A B S T R A C T}

\begin{tabular}{|c|}
\hline Keywords \\
\hline $\begin{array}{l}\text { Ischemia } \\
\text { /reperfusion, } \\
\text { Skeletal muscle, } \\
\text { Peripheral blood } \\
\text { mononuclear cells }\end{array}$ \\
\hline Article Info \\
\hline $\begin{array}{l}\text { Accepted: } \\
17 \text { September } 2020 \\
\text { Available Online: } \\
10 \text { October } 2020\end{array}$ \\
\hline
\end{tabular}

\section{Introduction}

Peripheral vascular disease is a major health problem that is considered as one of the most frequent causes of debilitating diseases. Lower limb ischemia is a life-threatening clinical condition resulting from hypovolemia or vascular occlusion. Reperfusion injury occurs when re-introduction of blood is allowed to the ischemic limbs causing unfortunately ischemia/reperfusion injury (IRI) (Hynes et al., 2012; Paradis et al., 2016).

\begin{abstract}
Lower limbs ischemia is a life-threatening condition resulting from hypovolemia or vascular occlusion. Peripheral blood mononuclear cells (PBMCs) may represent a novel treatment for ischemia reperfusion injury (IRI).This work was performed to study the effect of PBMCs on induced ischemia /reperfusion in skeletal muscle of adult male albino rat. Fifty adult male albino rats were used; twenty were considered as donors and the others as recipients. The recipients were divided into three groups. Group I served as a control. Group II used for induction of IRI; half of rats was sacrificed immediately (subgroup II-A) and the other half after 4 weeks (subgroup II-B).Group III: IRI induction was done then rats of subgroup III-A were injected with phosphate buffered saline while rats of subgroup III-B were treated by intramuscular injection of PBMCs. Rats of group III were sacrificed after 4 weeks. Muscle samples of all groups were processed for immunohistochemical study and morphological data were statistically analyzed. Rats treated with PBMCs showed well-evidenced repair of the skeletal muscle IRI.
\end{abstract}


Peripheral blood is a large accessible source of adult stem cells for both basic research and clinical applications. As there is a small number of mononuclear cells present in peripheral blood compared to their number in bone marrow (Zhang and Huang, 2012), numerous stem cells can be obtained from the peripheral blood after mobilizing them from bone marrow by using a granulocyte colony stimulating factor (G-CSF) (Wexler et al., 2003).

Mononuclear cells (MNCs) are a heterogeneous group of cells that contain mature $\mathrm{T} \& \mathrm{~B}$ lymphocytes and monocytes in addition to a plenty of different multipotent progenitor cells. MNCs transplantation has no need for in vitro culture that leads to increase the risk of contamination or repeated trials to obtain appropriate number for cell administration (Pösel et al., 2012). Until now, little information is known about the role of MNCs in tissues regeneration and few studies have been carried out to evaluate the effect of MNCs on muscle injuries. Subsequently, this work was done to demonstrate the effect of peripheral blood mononuclear cells on skeletal muscle regeneration after induced ischemia /reperfusion injury.

\section{Materials and Methods}

\section{Animals}

This study was carried out on 50 adult male albino rats of average weight 200 grams; twenty of them considered as donors while the others were used as recipients. Rats were housed in suitable clean properly ventilated cages under similar conditions and fed on a standard laboratory diet. They were acclimatized to their environment for two weeks before starting the experiment. All the steps of the experiment were performed at the Tissue Culture Unit of Histology Department, Faculty of Medicine, Tanta University after the approval of the Research Ethics Committee in Tanta Faculty of Medicine.

The donor rats were used for collection of peripheral blood for isolation of mononuclear cells. The donor rats were injected subcutaneously once a day with Neupogen that used as a G-CSF (Amgen Inc., One Amgen Center Drive, Thousand Oaks, California 91320-1799 U.S.A. US License No. 1080) by insulin syringe at a dose of $100 \mu \mathrm{g} / \mathrm{kg}$ for five consecutive days (Takagi et al., 2005). At the end of fifth day, the rats were anesthetized with ether inhalation then blood was collected by cardiac puncture after sterilization of thorax by alcohol (Parasuraman et al., 2010).

Then, the collected blood was processed for mononuclear cells isolation by density gradient centrifugation method using FicollHypaque. The cells were counted and injected intramuscularly for each recipient rat at a dose of $5 \times 10^{6}$ (Iwase et al., 2005).

\section{The recipient rats were divided into three groups (10 rats each) as follows}

Group I (control group): subdivided into subgroup I-A (5 rats) from which the gastrocnemius muscles were obtained without receiving any treatment and subgroup I-B (5 rats)from which the gastrocnemius muscles were obtained 4 weeks after their intramuscular injection once with $0.01 \mathrm{mlof}$ phosphate buffered saline (PBS).

Group II (ischemia reperfusion injury group; IRI): IRI was induced by applying a rubber tourniquet to the limb root of the right hind limb in each rat for 4 hours to induce ischemia, then the tourniquet was removed, and the limb was re-perfused for 1 hour(Edna et al., 2007). Five rats were immediately sacrificed after IRI induction and considered as a model for ischemia/reperfusion injury 
(subgroup II-A) while the other 5 rats were sacrificed after 4 weeks (subgroup II-B).

Group III (treated group):rats were subjected to induction of IRI as mentioned in group II. Subgroup III-A included 5 rats and they were injected IM once with $0.01 \mathrm{mlof}$ PBS by insulin syringe. Subgroup III-B included 5 rats and they were injected locally in the right gastrocnemius muscle once with peripheral blood mononuclear cells $\left(5 \times 10^{6}\right)$ suspended in $0.01 \mathrm{ml}$ PBS. In both subgroups, rats were sacrificed after 4 weeks.

\section{Tissue processing}

For histological study, musclespecimens were fixed in $10 \%$ formalin buffered saline and processed to get paraffin sections. Serial sections at 5 um thickness were cut using a microtome and mounted on positive charged slides for immunohistochemical staining for detection of myogenin and vascular endothelial growth factor (VEGF).

\section{Immunohistochemical study}

For immunohistochemical study, sections were de-paraffinized, rehydrated and covered by $3 \% \mathrm{H}_{2} \mathrm{O}_{2}$ for 10 minutes to block the activity of endogenous peroxidase to reduce nonspecific background staining. Then, they were treated with preheated citrate buffer $(\mathrm{PH}$ 6) for 20 minutes for antigen retrieval. Sections were incubated by $(50-80 \mu \mathrm{L})$ of the primary antibody (Rabbit monoclonal antibody to Myogenin) (EP162, Biogenex, Emergo Europe) overnight in a humidified chamber. Other sections were incubated by the primary antibody (Rabbit monoclonal antibody to VEGF) (EP1176Y, Gennova, Johan Gutenberg, India). After washing, the slides were covered completely by $(50-80$ $\mu \mathrm{L}$ ) of the secondary biotinylated goat antirabbit antibody. Subsequently, chromogenic substrate was applied (diaminobenzidine; DAB) and the slides were incubated until desired reaction was achieved. Mayer's hematoxylin was used as a counter stain.

Myogenin positive cells that represent differentiating myocytes showed a brown nuclear reaction. A section of rhabdomyosarcoma was used as a positive control and was provided by BiocareEmergo Europe. Normally, endothelial cells showed brown reaction in the nuclear membrane and cytoplasmic membranes to VEGF antibody. Expression of VEGF has been shown to be up regulated by any tissue in response to hypoxia, ischemia, hypoglycemia, inflammation, and malignancy. Tissue sections from kidney were used as a positive control and were provided by Abcam (Saad et al., 2005; Chen et al., 2011). Negative control sections were done by the same previous steps without adding the primary monoclonal rabbit antibody. Finally, all the specimens were examined and photographed using Leica light microscope with built in camera at Histology Department, Faculty of Medicine, Tanta University.

\section{Morphometric assessment}

The image analysis was done by using the software (Image J) (National Institute of Health, Bethesda, Maryland, USA). Ten different non-overlapping randomly selected fields from each slide were quantified for:

Number of Myogenin positive nuclei at a magnification power of 400 .

Capillary density is the number of capillaries/ $\mathrm{mm}^{2}$ was measured at a magnification power of 400.Capillaries were recognized as tubular structures positive for VEGF.

\section{Statistical analysis}

Data were analyzed using one-way analysis of variance (ANOVA) followed by Turkey's test for comparison between the groups using 
statistical package for Graph Pad Instate software (version 3, USA). All values were expressed as means \pm standard deviation. Differences were regarded as significant if probability $\mathrm{P}$-value $<0.05$ and highly significant if $\mathrm{P}$-value $<0.001$ (Dawson and Trapp, 2004).

\section{Results and Discussion}

\section{Immunohistochemical reaction of anti Myogenin}

Both Group I (control group) (Figure 1) and subgroup II-A (Figure 2) showed negative nuclear immune reactivity to myogenin while subgroup II-B(Figure 3) and subgroup IIIA(Figure 4) revealed some nuclei with positive immunoreactivity to myogenin. On the other hand, many nuclei with positive immunoreaction to myogenin were detected in rats treated with PBMCs (subgroup III-B), the nuclei were either peripheral or central in position (Figures 5a \& 5b).

\section{Immunohistochemical reaction of anti- vascular endothelial growth factor (VEGF)}

Group I (control group) showed negative reaction in the sarcoplasm and positive immuno reaction in the cytoplasm of endothelial cells (Figure 6).On the other hand, subgroup II-A showed diffuse strong positive reaction in the form of brownish color in the sarcoplasm of some muscle fibers (Figure 7). Positive reaction in the cytoplasm of endothelial cells of some dilated blood vessels (Figure 8a) in addition to localized positive reaction at the periphery of some muscle fibers (Figure 8b) was detected in subgroup II-B and subgroup III-A. Noteworthy, subgroup III-B that treated with PBMCs showed negative reaction in the sarcoplasm and appearance of the capillaries like that of control group with positive reaction in the cytoplasm of endothelial cells (Figure 9).

\section{Statistical results}

I - As regards mean number of myogenin positive nuclei; there was no significant difference $(p>0.05)$ in the mean number of myogenin positive nuclei of control group (subgroup IA, subgroup IB) and subgroup IIA. On the other hand, subgroup IIB $(2.9 \pm$ $2.424)$ and subgroup IIIA $(3 \pm 2.404)$ depicted a significant increase $(\mathrm{p}<0.05)$ compared to the control group. Mononuclear cells treated rats (subgroup IIIB) $(10.1 \pm 3.929)$ revealed a highly significant increase $(\mathrm{P}$ value $<0.001)$ in the mean number of myogenin positive nuclei when compared to all other subgroups. On the other hand, there was no significant difference $(p>0.05)$ between subgroup IIB and subgroup IIIA. All these data were illustrated in bar chart (1).

II - As regards mean number of blood capillaries, there was a highly significant decrease $(\mathrm{P}$ value < 0.001) in subgroup IIA $(60.61 \pm 27.992)$ and in subgroup IIB $(94.1 \pm 51.876)$ compared to control group. There was no significance difference ( $p$ > 0.05 ) in the mean number of blood capillaries in subgroup IIB compared to subgroup IIA and subgroup IIIA. On the other hand, mononuclear cells treated rats (subgroup IIIB) $(156.3 \pm 56.3)$ revealed a highly significant increase $(\mathrm{P}$ value $<0.001)$ when compared with subgroups IIA, IIB and IIIA. The mean number of blood capillaries in subgroup IIIB, that treated by MNCs, was non-significant ( $p$ $>0.05$ ) when compared to control group. All these data were illustrated in bar chart (2).

The skeletal muscle ischemia-reperfusion injury (IRI) is a life-threatening metabolic condition with high mortality and morbidity rates (Neto et al., 2014). Numerous intervention strategies including cell-based therapies have been proposed aiming to reduce IRI (Wang et al., 2015). To the best of our knowledge, this study could be considered 
the first one searching the effect of intramuscular injection of peripheral blood mononuclear cells (PBMCs) in ischemia reperfusion injury of skeletal muscle in experimental animals.

Chart.1 Comparison between the studied groups as regard means \pm SD of myogenin positive nuclei

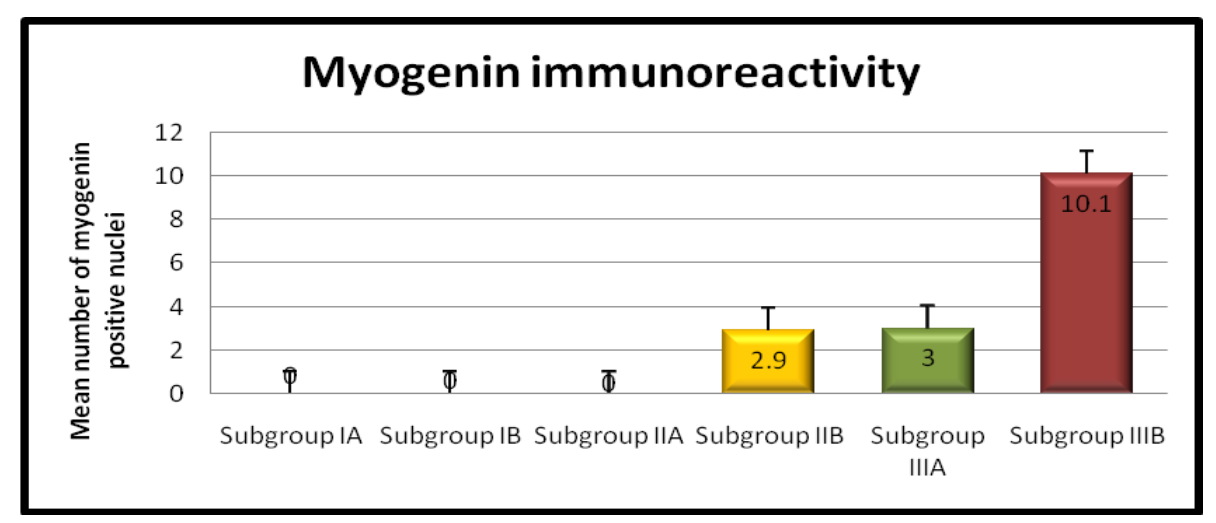

Chart.2 Comparison between the studied groups as regard means \pm SD of capillary density

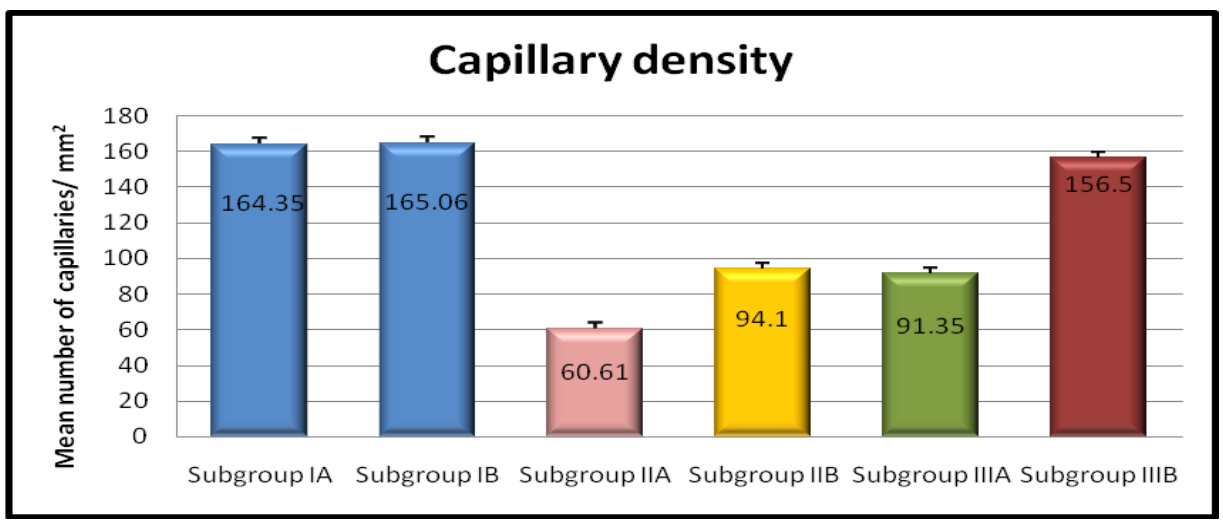

Fig.1 A longitudinal section in the gastrocnemius muscle of a control rat showing negative nuclear reaction (arrows)

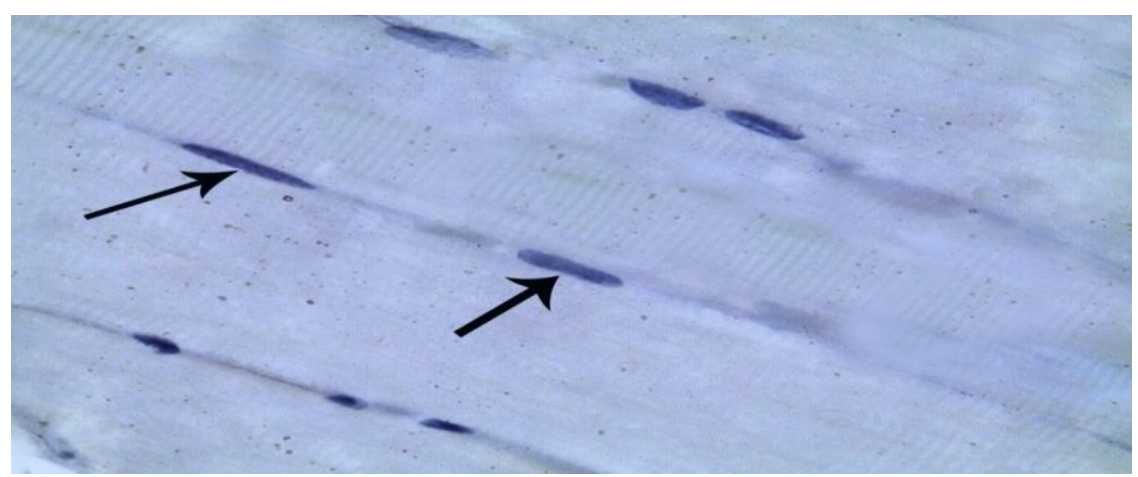

(Myogenin immunoreaction counterstained with $\mathrm{Hx}, \mathrm{x} 1000$ ) 
Fig.2 A longitudinal section in the gastrocnemius muscle of a rat in subgroup (II-A) showing negative nuclear reaction (arrows)

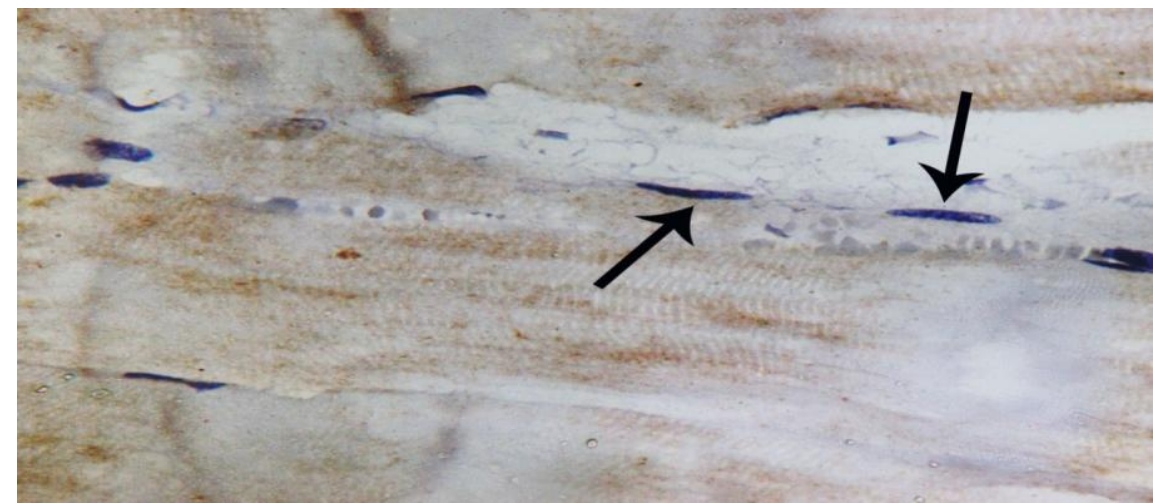

(Myogenin immunoreaction counterstained with Hx, x1000)

Fig.3 A longitudinal section in the gastrocnemius muscle of a rat in subgroup (II-B) showing some dark brown myogenin positive nuclei (arrows)

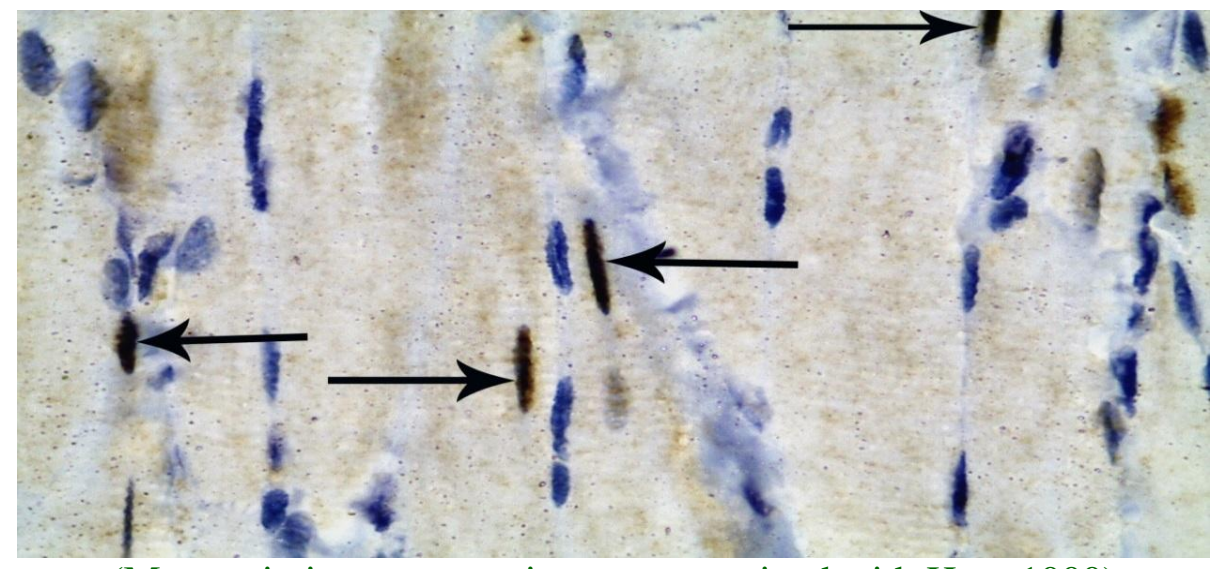

(Myogenin immunoreaction counterstained with Hx, x1000)

Fig.4 A longitudinal section in the gastrocnemius muscle of a rat in subgroup (III-A) showing some myogenin positive nuclei (arrows)

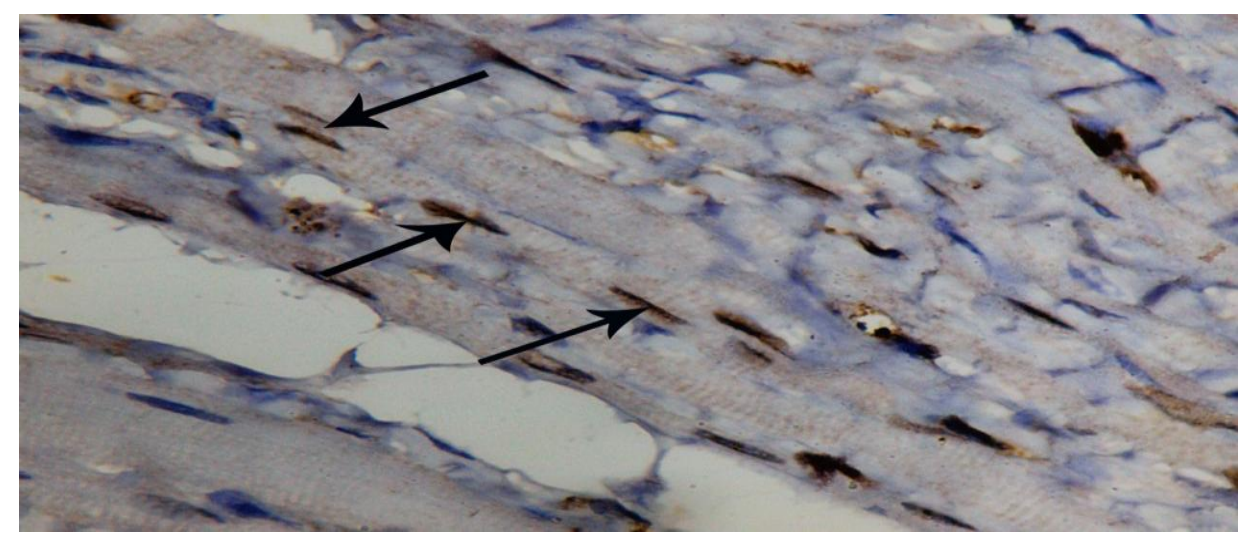

(Myogenin immunoreaction counterstained with Hx, x1000) 
Fig.5 Longitudinal sections in the gastrocnemius muscles of subgroup (III-B) showing numerous positive nuclei (arrows) arranged in rows either peripherally (A) or centrally (B) located

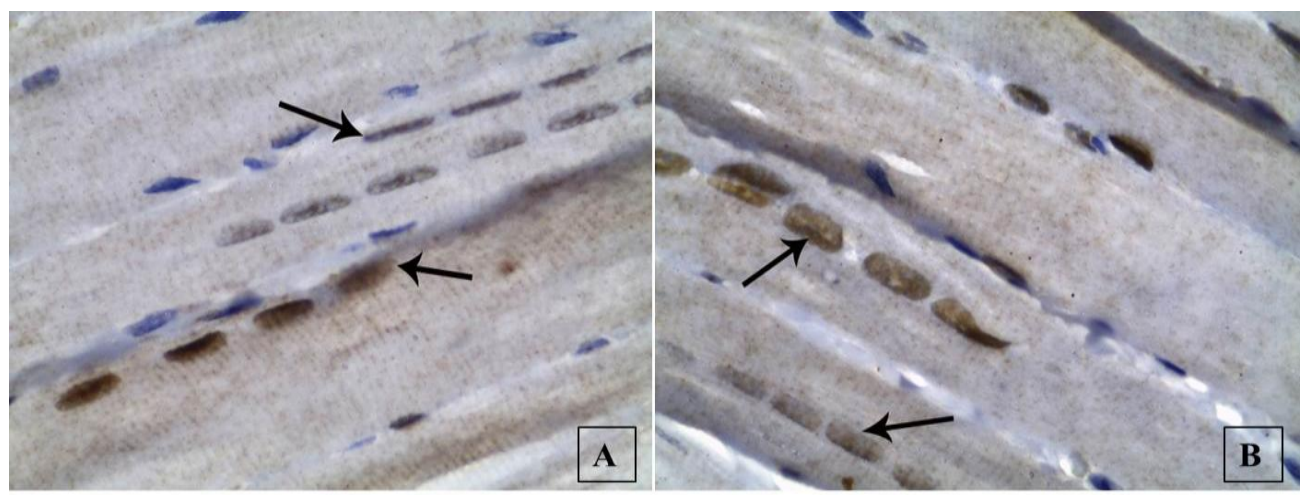

(Myogenin immunoreaction counterstained with Hx, x1000)

Fig.6 A transvers section in the gastrocnemius muscle of a control rat showing negative immunoreactivity in myofibers (stars) and positive reaction in the cytoplasm of endothelial cells (arrows)

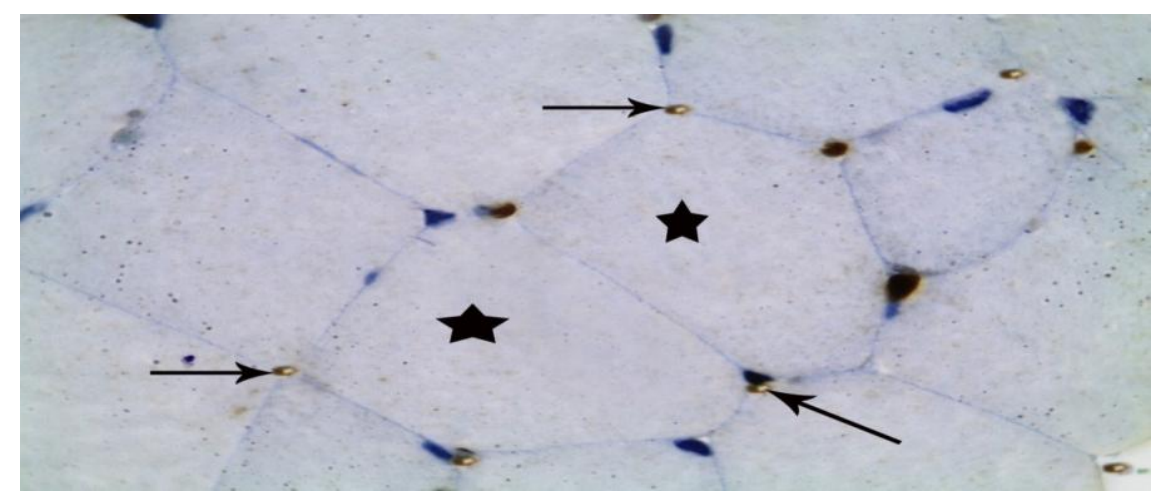

(VEGF immunoreaction counterstained with Hx, x1000)

Fig.7 A section in the gastrocnemius muscle obtained from a rat in subgroup (II-A) showing diffuse strong positive brown immunoreactivity in the sarcoplasm of muscle fibers (arrows)

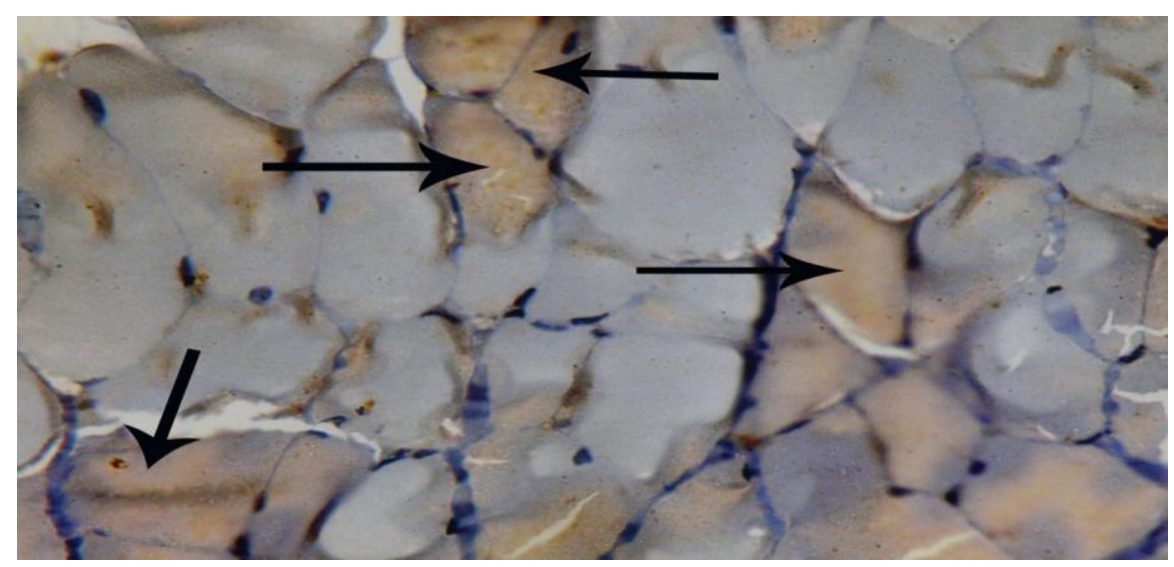

(VEGF immunoreaction counterstained with Hx, x1000) 
Fig.8 Sections in the gastrocnemius muscle of subgroup (II-B) showing (A): localized positive immunoreactivity at the periphery of some muscle fibers (arrows). (B): a positive reaction in the cytoplasm of endothelial cells (arrows)

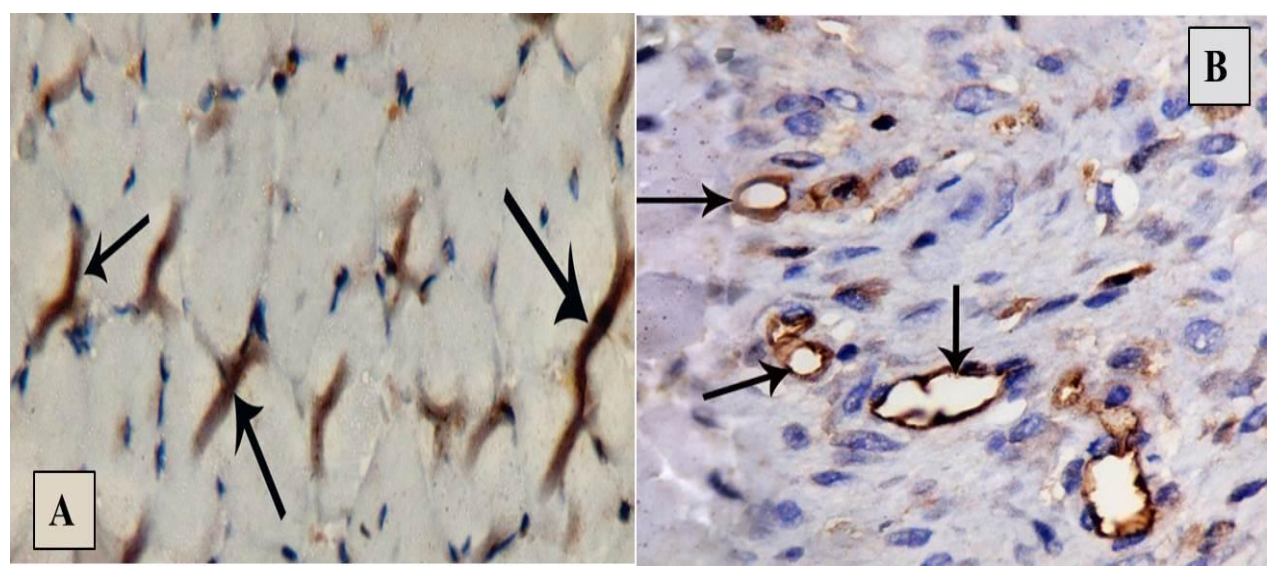

(VEGF immunoreaction counterstained with Hx, x1000)

Fig.9 A section in the gastrocnemius muscle of a rat in subgroup (III-B) showing a negative reaction in the sarcoplasm (stars) with positive reaction in the cytoplasm of endothelial cells (arrows)

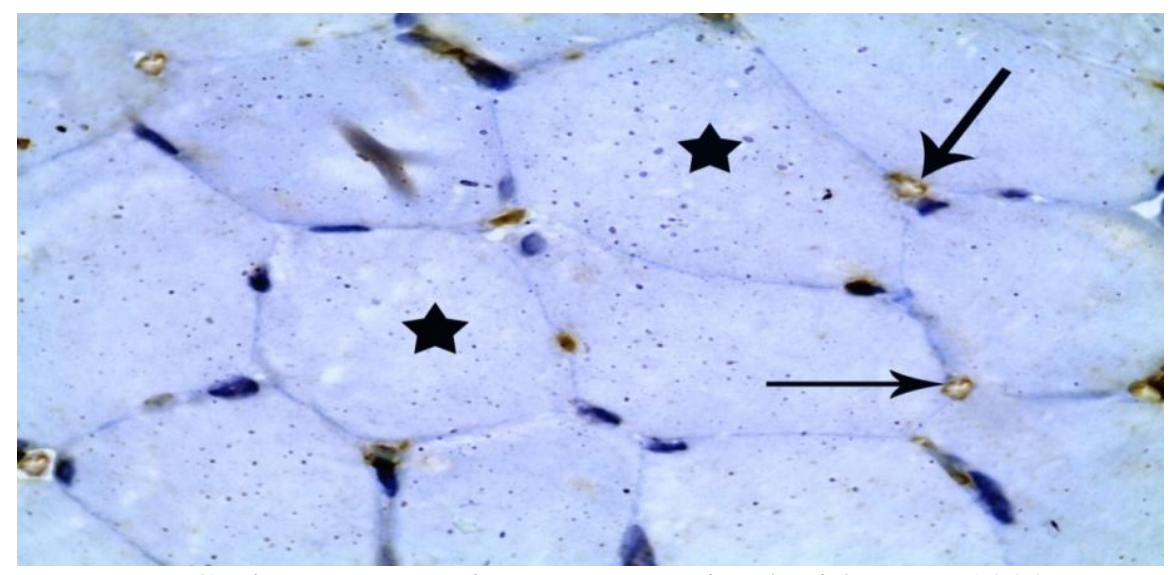

(VEGF immunoreaction counterstained with Hx, x1000)

In this study, differentiation of satellite cells was detected using myogen in immunostaining that revealed a significant increase in the mean number of myogen in immuno reacting cells in PBMCs treated rats (subgroup III-B) when compared with control group and IRI group. This was in accordance with the work of Christov et al., (2007) who reported that PBMCs produce more pronounced increase of myogenic precursor cells together with an expansion of the myogenic cell pool necessary for myofibers formation. Also, Youssef et al., (2015) and Nada et al., (2018) observed positive nuclei for myogenin and explained it as differentiating satellite cells overlapping the myofibers.

Moreover, Faralli and Dilworth (2012) stated that muscular injury activates satellite cells to divide and differentiate to specialized myogenic precursor cells expressing 
myogenin in attempt to repair the damaged muscle. In addition, Yin et al., (2013) and Wilschut et al., (2015) reported that myogenin is a specific gene that is essential for muscle development and regeneration. They added that, myogenin expression is restricted to cells of skeletal muscle origin but it is not detected in adult skeletal muscles. In addition, myogenin is an important indicator of differentiation of satellite cells.

In the present study, immunohistochemical staining for detection of VEGF in IRI group revealed a diffuse strong positive reaction in the sarcoplasm of ischemic muscle fibers in immediate sacrificed rats after induction (subgroup II-A). Meanwhile, the rats that were left for four weeks without treatment (subgroup II-B) showed a localized positive reaction at the periphery of myofibers sarcoplasm in addition to positive reaction in the cytoplasm of endothelial cells of dilated blood vessels. These findings were in accordance with the work of Rissanen et al., (2002) who noticed that diffuse expression of VEGF occurs in acute ischemia while in chronic skeletal muscle ischemia VEGF expression is restricted to atrophic and regenerating muscle cells.

In addition, Louboutin et al., (2012) stated that VEGF is found on the cell membrane, cytoplasm and nuclei of regenerating and atrophic skeletal muscle fibers. Moreover, Zhang et al., (2014) reported that VEGF is an angiogenic growth factor that was expressed in response to tissue ischemia and its role is mainly restricted to angiogenesis and endothelial cell growth.

Interestingly, in the present study peripheral blood mononuclear cells treated rats (subgroup III-B) showed many blood capillaries in the form of tubular structures with brownish endothelial cells in VEGF immunoreaction. PBMCs treated rats revealed higher number of capillaries in comparison with IRI group that was expressed by the term capillary density. The capillary density was counted as number of capillaries per $\mathrm{mm}^{2}$ according to a previous study done by Usui et al., (2014). Similarly, Wang et al., (2015) found that the capillary density in ischemic limbs was significantly greater in the PBMCs treated group than in the non-treated groups as evident using VEGF immunoreaction in the present study.

The therapeutic effect of PBMCs could be explained by Rehman et al., (2003) who suggested that PBMCs promote angiogenesis by activation of endothelial progenitor cell migration to the ischemic region and secrete several angiogenic factors that promote neovascularization in addition to cytokines, fibroblast growth factors and other factors that inhibit apoptosis.

In addition, Costa-Rodrigues et al., (2010) and Zhang and Huang (2012) reported that, mononuclear cells have the potential to differentiate into cell types other than phagocytes including; endothelial cells, hepatocytes, cardiomyogenic cells, smooth muscle cells, osteoblasts, osteoclasts, epithelial cells, neural cells, fat cells and skeletal muscle cells.

Moreover, Lee (2014) and Beer et al., (2016) added that PBMCs preparations, without any in-vitro manipulation, could be useful for tissue regeneration, because they contain immunomodulatory lymphocytes expressing various cytokines and paracrine factors called the cell secretomes that exert beneficial biological effects and promote tissue regeneration. On the other hand, Ceafalan et al., (2018) stated that the implanted mononuclear cells do not secrete angiogenic factors sufficient for neovascularization but instead stimulate muscle cells to produce angiogenic factors, thereby promoting 
neovascularization in ischemic tissues.

From the previous data, it was concluded that PBMCs had a significant effect on enhancement of muscle regeneration after IRI. This effect was obtained by promoting proliferation, activation and differentiation of satellite cells in addition to neovascularization and formation of multiple capillaries. Accordingly, using PBMCs as a promising treatment option to promote skeletal muscle repair in peripheral arterial disease can become a reality in the near future.

\section{Acknowledgments}

There is no conflict of interest. This research did not receive any specific grant from funding agencies in the public, commercial, or not-for-profit sectors.

\section{Declaration of interest}

All authors declare no related conflicts of interest.

\section{References}

Beer, L., Mildner, M., Gyöngyösi, M.,and Ankersmit, HJ. 2016. Peripheral blood mononuclear cell secretome for tissue repair. Apoptosis; 21(12): 1336-1353.

Ceafalan, LC., Fertig, TE., Popescu, AC., Popescu, BO., Hinescu, ME., and Gherghiceanu, M. 2018. Skeletal muscle regeneration involves macrophagemyoblast bonding. Cell Adhesion \& Migration; 12(3): 228-235.

Chen, L., Huang, HW., Gu, SH., Xu, L., Gu, YD., $\mathrm{Xu}, \mathrm{JG}$., and $\mathrm{Xu}, \mathrm{JG} .2011$. The study of myogenin expression in denervated human skeletal muscles. Journal of International Medical Research; 39(2): 378-387.

Christov, C., Chrétien, F., Abou-Khalil, R., Bassez, G., Vallet, G., Authier, FJ., Bassaglia, Y., Shinin, V., Tajbakhsh, S.,
Chazaud, B.,and Gherardi, RK. 2007. Muscle satellite cells and endothelial cells: close neighbors and privileged partners. Molecular Biology of the Cell; (4): 1397-1409.

Costa-Rodrigues, J., Teixeira, CA., Sampaio, P., and Fernandes, MH. 2010. Characterisation of the osteoclastogenic potential of human osteoblastic and fibroblastic conditioned media. J Cell Biochem; 109: 205-216.

Dawson, B., and Trapp, R.2004. Research questions about relationships among variables. (Ch.8). In basic \& clinical biostatistics. The McGraw-Hill Companies. USA; pp 190-220.

Edna, M., Maeli, D., Vitalino, P., Rubens, C., and Ana Lucia, A. 2007. Ischemia and reperfusion effects on skeletal muscle tissue: morphological and histochemical studies. Int J Exp Path; 88: 147-154.

Faralli, H., and Dilworth, FJ.2012. Turning on Myogenin in Muscle: A Paradigm for Understanding Mechanisms of TissueSpecific Gene Expression. Comp Funct Genomics; 2012: 836374.

Hiatt, WR., Armstrong, EJ., Larson, CJ., and Brass, EP. 2015. Pathogenesis of the limb manifestations and exercise limitations in peripheral artery disease. Circulation Research; 116(9): 15271539.

Hynes, BG., Margey, RJ., Ruggiero Ii, N., Kiernan, TJ., Rosenfield, K, and Jaff, MR. 2012. Endovascular management of acute limb ischemia. Annals of Vascular Surgery; 26(1): 110-124.

Iwase, T., Nagaya, N., Fujii, T., Itoh, T., Murakami, S., Matsumoto, T., Kangawa, K., and Kitamura, S.2005. Comparison of angiogenic potency between mesenchymal stem cells and mononuclear cells in a rat model of hindlimb ischemia. Cardiovascular Research; 66(3): 543-551.

Kilıç, Y., Özer, A., Tatar, T., Zor, 
MH.,Kirisci, M., Kartal, H., Dursun, AD., Billur, D., Arslan, M., and Kucuk, A. 2017. Effect of picroside II on hind limb ischemia reperfusion injury in rats. Drug Des DevelTher; 11: 1917-1925.

Lee, YH. 2014. Regenerative Potential of Intravenous Infusion with Mononuclear Cells in Cord Blood and G-CSFMobilized Peripheral Blood. J Stem Cell Res Ther; 4: 224.

Louboutin, JP.,Marusich, E., Gao, E., Agrawal, L., Koch, WJ., and Strayer, DS.2012. Ethanol protects from injury due to ischemia and reperfusion by increasing vascularity via vascular endothelial growth factor. Alcohol; 46(5): 441-454.

Nada, SM., El-Deeb, DF., AboulKhair, AG., and Hosny, SA. 2018. A histological Study Comparing the Possible Protective Mechanisms of Oxytocin and Vitamin E on ischemia reperfusion injury in Rat skeletal muscle. Egyptian Journal of Histology; 41(4): 570-581.

Neto, F., da Silva, CA., Koike, MK., Saad, KR., Saad, PF., and Montero, EF.2014. Effects of ischemic preconditioning and cilostazol on muscle ischemiareperfusion injury in rats. ActaCirurgicaBrasileira; 29: 17-21.

Paradis, S., Charles, AL., Meyer, A., Lejay, A., Scholey, JW., Chakfé, N., Zoll, J., and Geny, B. 2016. Chronology of mitochondrial and cellular events during skeletal muscle ischemiareperfusion. American Journal of Physiology-Cell Physiology; 310(11): 968-982.

Parasuraman, S., Raveendran, R., and Kesavan, R. 2010. Blood sample collection in small laboratory animals. Journal of Pharmacology \& Pharmaco Therapeutics; (2): 87.

Pösel, C., Möller, K., Fröhlich, W., Schulz, I., Boltze, J. and Wagner, DC.2012. Density gradient centrifugation compromises bone marrow mononuclear cell yield. PloS One; 7(12): e50293.

Rehman, J., Li, J., Orschell, CM., and March, KL. 2003. Peripheral blood "endothelial progenitor cells" are derived from monocyte/macrophages and secrete angiogenic growth factors. Circulation; 107(8): 1164-1169.

Rissanen, TT., Vajanto, I., Hiltunen, MO., Rutanen, J., Kettunen, MI., Niemi, M., Leppanen, P., Turunen, MP., Markkanen, JE., Arve, K., Alhava, E., Kauppinen, RA., and Yla“-Herttuala, S. 2002. Expression of Vascular Endothelial Growth Factor and Vascular Endothelial Growth Factor Receptor-2 (KDR/Flk-1) in Ischemic Skeletal Muscle and Its Regeneration. Am J Pathol; 160(4):1393-1403.

Saad, RS., El-Gohary, Y., Memari, E., Liu, YL., and Silverman, JF. 2005. Endoglin (CD105) and vascular endothelial growth factor as prognostic markers in esophageal adenocarcinoma. Hum Pathol; 36: 955-961.

Takagi, Y., Omura, T., Yoshiyama, M., Matsumoto, R., Enomoto, S., Kusuyama, T., Nishiya, D., Akioka, K., Iwao, H., Takeuchi, K., and Yoshikawa, J. 2005. GranulocyteColony Stimulating Factor Augments Neovascularization Induced by Bone Marrow Transplantation in Rat Hind limb Ischemia. J PharmacolSci; 99: 45 51.

Usui, S., Iso, Y., Sasai, M., Mizukami, T., Sato, C., Kurata, M., Umezawa, A., Shioda, S., and Suzuki, H.2014. Mesenchymal stem cells from bone marrow enhance neovascularization and stromal cell proliferation in rat ischemic limb in the early phase after implantation. The Showa University Journal of Medical Sciences; 26(2): 121129.

Wang, XT., Tian, Y., Xu, WX., Cui, LH., 
Xiang, SY., and Lü, SC. 2015.Protective Effects of Modeled Superoxide Dismutase Coordination Compound (MSODa) Against Ischemia/ Reperfusion Injury in Rat Skeletal Muscle. Cell Physiol Biochem; 37(2): 465-476.

Wexler, SA., Donaldson, C., DenningKendall, P., Rice, C., Bradley, B., and Hows, JM. 2003. Adult bone marrow is a rich source of human mesenchymal 'stem' cells but umbilical cord and mobilized adult blood are not. $\mathrm{Br} \mathrm{J}$ Haematol; 121: 368-374.

Wilschut, KJ., Gong, W., Oishi, PE., and Bernstein, HS. 2015. Derivation of Engrafting Skeletal Muscle Precursors from Human Embryonic Stem Cells Using Serum-Free Methods. J Stem Trans Bio.; 1(1): 106.

Yin, H., Price, F. andRudnicki, MA. 2013. Satellite Cells and the Muscle Stem Cell
Niche. Physiol Rev; 93(1): 23-67. Youssef,MF., Zickri, MB., Gamal, M., Yassin, N., AbdElAl, L., and Elhadary, N. 2015. Effect of Exercise Training on Endogenous Stem Cells Activation in Ischemia Reperfusion Induced Skeletal Muscle Injury: A Physio-Histological Study. Journal of Cytology \& Histology; 6(4): 1 .

Zhang, M., and Huang, B.2012.The multidifferentiation potential of peripheral blood mononuclear cells. Stem Cell Research \& Therapy; 3(6): 48.

Zhang, M., Gao,X., Bai, SJ., Ye, XM., and Zhang, J. 2014.Effect of pioglitazone on expression of hypoxia-inducible factor $1 \alpha$ and vascular endothelial growth factor in ischemic hind limb of diabetic rats. Eur Rev Med Pharmacol Sci.; 18(9): 1307-1314.

\section{How to cite this article:}

Hend I. Abd El Halim, Reda H. Elbakary, Ebtsam F. Okasha, Amany M. Mousa and Ehsan F. Salah. 2020. Effect of Peripheral Blood Mononuclear Cells on Induced Ischemia/Reperfusion in Skeletal Muscle of Adult Male Albino Rat: An Immunohistochemical Study. Int.J.Curr.Microbiol.App.Sci. 9(10): 2133-2144. doi: https://doi.org/10.20546/ijcmas.2020.910.260 